\title{
THE ELABORATION OF OSMOTICALLY CONCENTRATED URINE IN RENAL DISEASE
}

\author{
BY DAVID S. BALDWIN, HAROLD J. BERMAN, HENRY O. HEINEMANN, \\ AND HOMER W. SMITH
}

\begin{abstract}
(From the Departments of Medicine ${ }^{1}$ and Physiolocy. New York University College of Medicine, and Third (Now York University) Medical Division, Belleoue Hospital, New York, N. Y.)
\end{abstract}

(Submitted for publication January 6, 1955 ; accepted January 26, 1955)

During the hydropenic state, the kidney, in the interest of water conservation, excretes a urine which is osmotically more concentrated than the blood. Since the glomerular filtrate has the same osmotic pressure as the plasma, in the elaboration of an osmotically concentrated urine the renal tubules must remove from this isosmotic filtrate a certain quantity of solute free water. The quantity of water so removed from any sample of urine is given by the difference between the volume of urine required to contain the urinary solutes in an isosmotic state, or the osmolar clearance, $\mathrm{C}_{\text {oom }}$, and the urine-flow, $\mathrm{V}$ (1). The osmolar clearance is given by the calculation $U_{o o m} V / P_{o o m}$, where $U_{o s m}$ and $P_{\text {oem }}$ are the osmotic concentrations of the urine and plasma, respectively, and $\mathrm{V}$ is the urine flow in cc. per min. Hence the solute-free water, $T_{\mathrm{H}_{5}}^{c} \mathrm{O}$, removed by the tubules in concentrating the urine is

$$
\mathrm{T}_{\mathrm{H}_{2} \mathrm{O}}^{\mathrm{O}}=\frac{\mathrm{U}_{\text {oem }} \mathrm{V}}{\mathrm{P}_{\text {oem }}}-\mathrm{V}
$$

This concentrating operation is subject to two limitations. Zak, Brun, and Smith (2) have shown that at large urine flows induced by osmotic diuresis in the antidiuretic state, $T_{\mathrm{H}_{2} \mathrm{O}}^{c_{2}}$ attains an approximately constant value, $\mathbf{T m}_{\mathrm{H}}^{\mathrm{c}} \mathrm{O}$. At lower urine flows, however, when $\mathrm{C}_{\text {oom }}$ is less than $\mathrm{Tm}_{\mathrm{H}_{2} \mathrm{O}}^{\mathrm{c}}$, the reabsorption of solute-free water proceeds until the urine approaches a maximal osmotic concentration, or (what is equally probable) until the osmotic $U / P$ ratio approaches a maximal value, which in normal subjects is about 4.0 (3).

It has long been conventional to judge the

1 Aided in part by a grant from the New York Heart Association.

2 This investigation was supported in part by a research grant (H-1172 (c)) from the National Heart Institute of the National Institutes of Health, Public Health Service. concentrating operation of the kidney by the specific gravity of the urine, but specific gravity is not an appropriate index for this purpose because it does not accurately reflect the basic physiological operation of the kidney, which can only be judged in terms of the quantity of water abstracted.

In the present study, the concentrating operation, as evaluated by $\mathrm{T}_{\mathrm{H}_{2} \mathrm{O}}^{\mathrm{c}}$, has been examined in patients with acute and chronic renal disease.

\section{METHODS}

Our subjects comprise 25 patients, drawn from various services of Bellevue Hospital, with the following diagnoses: acute glomerulonephritis, 5; chronic glomerulonephritis, 14; chronic pyelonephritis, 1; Kimmelstiel-Wilson syndrome, 2; and acute renal failure, 3. All subjects were maintained on the regular hospital diet except for variations in salt intake. Fluids were withheld during 15 to 18 hours preceding the test, which was performed in the morning with the patient in a fasting state. Urine was collected by means of an indwelling catheter, and residual urine was expelled from the bladder by means of air. No washout fluid was used. Surgical sterility was maintained throughout the test.

Control urine and plasma samples were collected for the determination of inulinoid blank and oliguric osmotic $U / P$ ratio. After priming doses of inulin ( \pm 3.0 grams) and of Pitressin (Parke, Davis and Co.) (50 to 100 milliunits) had been administered intravenously, an infusion containing inulin and Pitressin (3) was established, the latter being administered at a rate of 1 milliunit per $\mathrm{kg}$. of body weight per hour. The rate of infusion of inulin was adjusted to maintain a plasma concentration of ca. $25 \mathrm{mg}$. per $100 \mathrm{cc}$.

Urine was collected for three periods of 15 to 20 minutes each for the determination of the basal filtration rate and osmotic U/P ratio. Thereafter, progressively increasing osmotic diuresis was induced by administration of 10 per cent mannitol solution at a rate of 10 to $20 \mathrm{cc}$. per min. into the infusion tubing, the infusion of inulin and Pitressin being continued throughout. Urine collection was continued for 6 to 10 periods of 10 minutes each, and blood was drawn at appropriate intervals from an antecubital vein into heparinized syringes, centrifuged immediately and the plasma stored in stoppered tubes. 
Inulin was determined by Schreiner's modification of the resorcinol method of Roe (4), and osmotic pressure of plasma and urine was determined by means of the thermistor bridge-null-point-detector unit of Bowman, Trantham, and Caulfield (5), using a Johlin freezing point apparatus (6). Urine specific gravity was determined with a clinical urinometer, if the urine volume was adequate; otherwise the specific gravity was determined by weighing the sample.

\section{RESULTS}

When the osmolar clearance, $\mathrm{C}_{\text {oum }}$, approaches or is less than the maximal value of $T_{H_{s}}^{c}$, the concentrating mechanism is not "saturated" and solute-free water reabsorption becomes limited by an approach to the limiting osmotic $U / P$ ratio. It is therefore necessary to consider in each instance whether $C_{\text {oem }}$ is large enough to fulfill the condition that $T_{\mathrm{H}_{3} \mathrm{O}}^{\mathrm{c}}$ is maximal, or approximately so. To this end, in considering the data for each subject, $\mathrm{C}_{\text {oom }}$ was plotted against $\mathrm{V}$, as in Figure 1, which shows a series of observations in subject No. 10. The nature of this graph is such that if the urine were consistently isosmotic with the plasma, $\mathrm{C}_{\text {osm }}$ would always be equal to $\mathrm{V}$ and all points would fall on the bisector, or isosmotic parameter (7). In so far as the data are displaced to the left of the isosmotic parameter, it is inferred (2) that solute-free water has been abstracted from isosmotic glomerular filtrate to an extent equal to the leftward, horizontal displacement (line $b$ in Figure 1 ).

The first three points at the left of Figure 1 generate a straight line a which intersects the zero coordinates, and represents a constant osmotic $U / P$ ratio-in this subject having a value of 1.90. At higher values of $V, T_{\text {Ho }}^{c}$ reaches an approximately constant value, $\mathrm{Tm}_{\mathrm{H}, \mathrm{O}}^{\mathrm{C}}$. In this

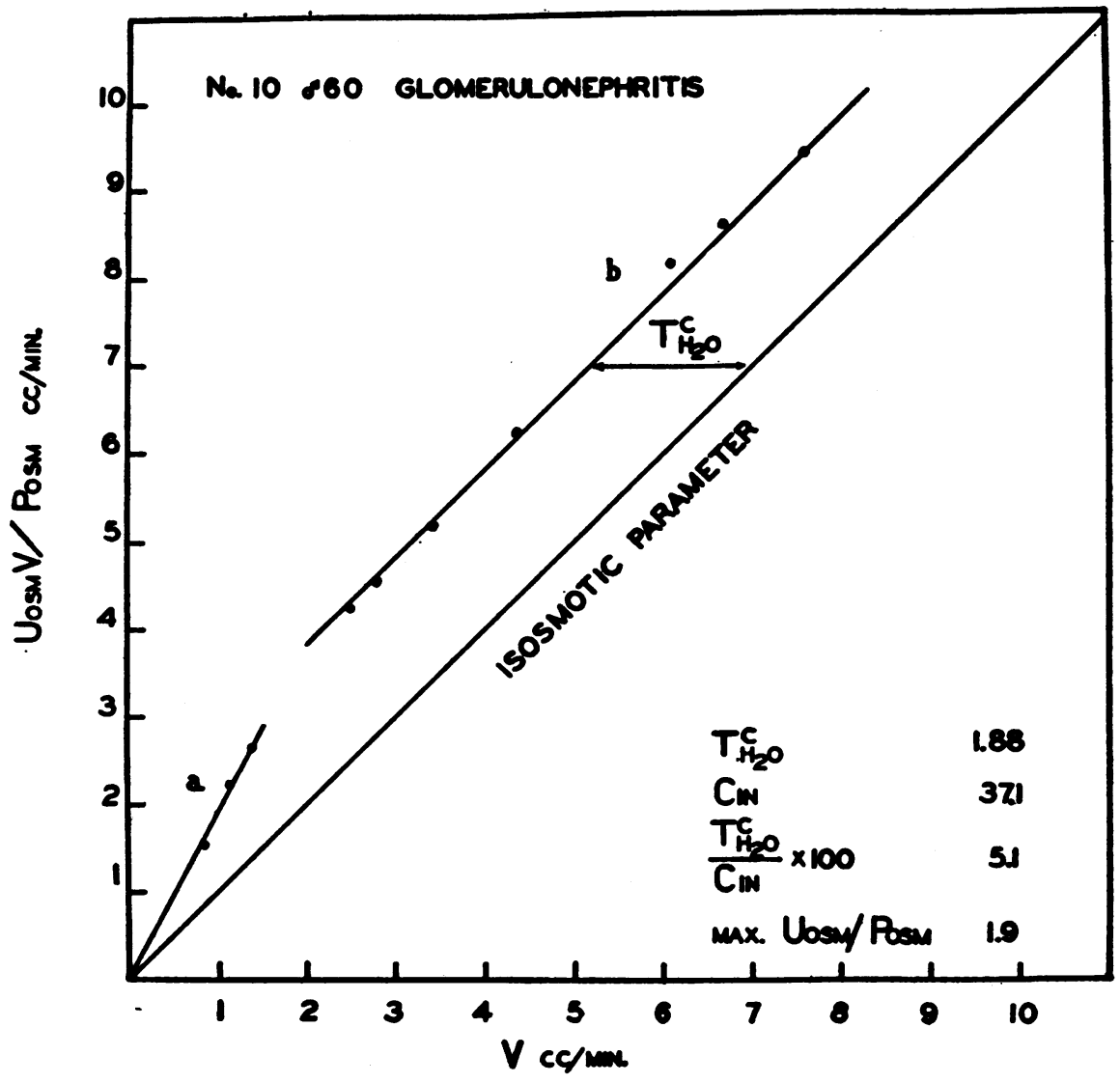

Fig. 1. Urinary Concentrating Process in a 60-Year Old Male with Chronic Glomerulonephrits

Patient studied during hydropenic state with mannitol osmotic diuresis and Pitressin administration. 
TABLE I

Osmotic diuresis during hydropenia and Pitressin (3) administration in 19 patients with acute or chronic glomerulonephritis

\begin{tabular}{|c|c|c|c|c|c|c|c|c|c|c|c|c|c|c|}
\hline$\frac{1}{\text { No. }}$ & $\begin{array}{c}2 \\
\text { Age } \\
y r s .\end{array}$ & sex $^{3}$ & $\begin{array}{l}\text { 4 } \\
\text { Surface } \\
\text { area } \\
\text { sq. } m .\end{array}$ & $\stackrel{5}{5}$ & $\underset{\substack{\text { Poem } \\
\text { range } \\
\text { OOsm./L. }}}{\text {. }}$ & $\begin{array}{c}7 \\
\text { Urine } \\
\text { flow } \\
\text { range } \\
\text { cc./min. }\end{array}$ & $\begin{array}{c}8 \\
\mathrm{CIN} \\
\text { per } 1.73 \\
8 \mathrm{sq} . \mathrm{m} . \\
c c . / \mathrm{min} .\end{array}$ & $\begin{array}{c}9 \\
\text { Regres. } \\
\text { coef. } \\
\text { (slope) }\end{array}$ & $\begin{array}{l}10 \\
\text { Correl. } \\
\text { coef. } \\
r\end{array}$ & $\begin{array}{c}11 \\
\operatorname{Tm}_{\mathrm{HsO}}^{\circ} \\
\text { per } 1.73 \\
8 \mathrm{~s} . \mathrm{m} . \\
c c . / \mathrm{min} .\end{array}$ & $\begin{array}{c}12 \\
\mathrm{Tm}_{\mathrm{HgO}}^{\circ} / \\
\mathrm{C}_{\text {Int }} \\
\times 100\end{array}$ & $\underset{\substack{\text { Maximalt } \\
\text { gpecific } \\
\text { gravity }}}{13}$ & $\underset{\substack{\text { Maximalt } \\
\text { Uoma }}}{14}$ & $\begin{array}{l}15 \\
\text { v/Crn } x \\
\text { 100 (at } \\
\text { maximal } \\
\text { diuresis) } \\
\text { per cent }\end{array}$ \\
\hline \multirow[t]{2}{*}{$\begin{array}{r}15 \\
19 \\
30 \\
26 \\
37 \\
21 \\
34 \\
25 \\
8 \\
5 \\
29 \\
6 \\
7 \\
38 \\
2 \\
10 \\
35 \\
3 \\
32\end{array}$} & $\begin{array}{r}8 \\
7 \\
38 \\
37 \\
39 \\
12 \\
35 \\
42 \\
12 \\
54 \\
57 \\
29 \\
65 \\
49 \\
12 \\
60 \\
37 \\
62 \\
27\end{array}$ & $\begin{array}{l}\mathbf{F} \\
\mathbf{M} \\
\mathbf{F} \\
\mathbf{F} \\
\mathbf{M} \\
\mathbf{F} \\
\mathbf{F} \\
\mathbf{M} \\
\mathbf{M} \\
\mathbf{M} \\
\mathbf{F} \\
\mathbf{F} \\
\mathbf{M} \\
\mathbf{F} \\
\mathbf{F} \\
\mathbf{M} \\
\mathbf{M} \\
\mathbf{M} \\
\mathbf{M}\end{array}$ & $\begin{array}{l}1.01 \\
0.89 \\
1.82 \\
1.62 \\
2.00 \\
1.33 \\
1.32 \\
1.69 \\
1.05 \\
1.95 \\
1.75 \\
1.56 \\
1.73 \\
1.56 \\
1.04 \\
1.74 \\
1.69 \\
2.02 \\
1.90\end{array}$ & $\begin{array}{l}\text { Acute } \\
\text { Acute } \\
\text { Acute } \\
\text { Chronic } \\
\text { Acute } \\
\text { Chronic } \\
\text { Chronic } \\
\text { Acute } \\
\text { Chronic } \\
\text { Chronic } \\
\text { Chronic } \\
\text { Chronic } \\
\text { Chronic } \\
\text { Chronic } \\
\text { Chronic } \\
\text { Chronic } \\
\text { Chronic } \\
\text { Chronic } \\
\text { Chronic }\end{array}$ & $\begin{array}{l}305-322 \\
267-288 \\
280-288 \\
265-287 \\
287-299 \\
304-308 \\
277-301 \\
294-297 \\
299-321 \\
284-292 \\
290-305 \\
272-286 \\
308-317 \\
285-289 \\
296-304 \\
302-316 \\
283-306 \\
301-307 \\
302-320\end{array}$ & $\begin{array}{l}2.4-8.9 \\
3.1-8.6 \\
5.4-7.9 \\
3.8-14.6 \\
9.1-30.9 \\
4.9-12.5 \\
3.7-9.7 \\
4.1-7.6 \\
2.2-15.8 \\
2.9-12.7 \\
7.7-9.6 \\
2.0-6.5 \\
1.9-7.0 \\
4.9-23.2 \\
2.3-6.1 \\
2.5-7.6 \\
2.2-1.5 .5 \\
1.9-3.7 \\
2.0-4.3\end{array}$ & $\begin{array}{l}88.9 \\
78.6 \\
78.6 \\
73.2 \\
72.4 \\
71.3 \\
70.8 \\
68.4 \\
62.3 \\
57.5 \\
53.6 \\
46.7 \\
41.0 \\
39.8 \\
38.3 \\
37.1 \\
23.0 \\
14.1 \\
12.8\end{array}$ & $\begin{array}{l}1.197 \\
1.286 \\
1.159 \\
1.183 \\
0.958 \\
1.258 \\
1.002 \\
1.166 \\
1.019 \\
1.128 \\
0.905 \\
1.056 \\
1.003 \\
1.068 \\
1.011 \\
1.059 \\
0.877 \\
0.935 \\
1.132\end{array}$ & $\begin{array}{l}.9915 \\
.9999 \\
.9099 \\
.9908 \\
.9841 \\
.9975 \\
.9673 \\
.9431 \\
.9967 \\
.9913 \\
.9999 \\
.9996 \\
.9988 \\
.9924 \\
.9927 \\
.9999 \\
.9905 \\
.9996 \\
.9993\end{array}$ & $\begin{array}{l}6.03 \\
6.96 \\
4.90 \\
5.09 \\
4.79 \\
5.52 \\
3.76 \\
4.19 \\
3.43 \\
1.63 \\
3.18 \\
1.40 \\
2.15 \\
1.99 \\
1.18 \\
1.88 \\
0.448 \\
0.21 \\
0.78\end{array}$ & $\begin{array}{l}6.8 \\
8.8 \\
6.2 \\
6.9 \\
6.6 \\
7.8 \\
5.3 \\
6.1 \\
5.5 \\
2.8 \\
5.9 \\
3.0 \\
5.2 \\
5.0 \\
3.1 \\
5.1 \\
1.9 \\
1.5 \\
6.1\end{array}$ & $\begin{array}{l}\overline{1.015} \\
1.028 \\
\overline{1.014} \\
\overline{1.013} \\
\overline{1} \\
1.026 \\
1.011 \\
1.018 \\
\overline{-} \\
\overline{1} \\
1.013 \\
\overline{1.017} \\
1.010 \\
1.020\end{array}$ & $\begin{array}{l}3.06 \\
3.28 \\
3.10 \\
3.24 \\
2.30 \\
1.87 \\
2.50 \\
2.30 \\
2.65 \\
1.72 \\
2.01 \\
1.85 \\
2.70 \\
1.59 \\
1.46 \\
1.90 \\
1.23 \\
1.15 \\
1.51\end{array}$ & $\begin{array}{r}16.8 \\
15.6 \\
8.9 \\
20.8 \\
31.6 \\
22.1 \\
30.7 \\
10.2 \\
15.6 \\
19.2 \\
15.8 \\
12.6 \\
15.2 \\
46.2 \\
26.5 \\
22.7 \\
50.0 \\
21.6 \\
27.6\end{array}$ \\
\hline & & & & $\begin{array}{l}\text { Mean } \\
\text { S.D. }\end{array}$ & $290-302$ & $3.6-11.2$ & 54.2 & $\begin{array}{l}1.074 \\
0.113\end{array}$ & $\begin{array}{l}.9866 \\
.0226\end{array}$ & 3.13 & $\begin{array}{l}5.2 \\
1.9\end{array}$ & - & - & - \\
\hline
\end{tabular}

* Numbers refer to the case histories and do not reflect the number of experiments done in this study.

t Ratio based on control $C_{\text {IN }}$.

$\mp$ Not on same urine samples.

Urine hypotonic to the blood at urine flows above 10.7 cc. per min. Recorded $\mathrm{Tm}_{\mathrm{H}_{2} \mathrm{O}}^{\mathrm{O}}$ is highest value observed at low urine flows.

particular subject the deviation from constancy is indicated by the fact that the regression line of $\mathrm{C}_{\text {osm }}$ on $\mathrm{V}$ has a slope of 1.059 rather than 1.0. It was found (2) that the slope of this regression line in subjects with normal renal function frequently deviated significantly from 1.0 , and it was arbitrarily elected to measure $\mathrm{Tm}_{\mathrm{H}, \mathrm{O}}^{\mathrm{c}}$ for comparative purposes: when $\mathrm{V}=20 \mathrm{cc}$. per min. In our subjects with reduced renal function we have seldom attained urine flows of this magnitude, and therefore we have arbitrarily elected to take, as the definitive value of $\mathrm{Tm}_{\mathrm{H}_{2} \mathrm{O}}^{\mathrm{c}}$, the mean of all values within the range of $\mathrm{V}$ where the regression of $\mathrm{C}_{\text {osm }}$ on $\mathrm{V}$ is linear, regardless of the slope of the regression line. In the subject illustrated in Figure 1, the value of $\mathrm{Tm}_{\mathrm{H}_{3} \mathrm{O}}^{\mathrm{c}}$ is $1.88 \mathrm{cc}$. per min. per 1.73 sq. m. body surface area.

Observations in 19 patients with acute or chronic glomerulonephritis are presented in Table I. Columns 1 to $\mathbf{5}$ are self explanatory. Column 6 shows the extremes of plasma osmolarity during the period of observation, and column 7 the range of urine flow involved in the calcula- tions shown in columns $8,9,10$, and 11 . Column 8 indicates the average inulin clearance $\left(\mathrm{C}_{\mathrm{IN}}\right)$ for three urine collection periods preceding the mannitol infusion. In 6 of the 19 patients, $C_{I N}$ increased by more than 20 per cent during osmotic diuresis, the maximal increase being 37 per cent in subject No. 35 .

Turning to derivative calculations, column 9 gives the slope of the regression line (or the regression coefficient) generated by $\mathrm{C}_{\text {osm }}$ on $\mathrm{V}$. The mean slope for these 19 patients is $1.074 \pm$ 0.113 . In 9 subjects the slope falls outside the range of 0.90 to 1.10 ; it exceeds 1.10 in 8 subjects, and is less than 0.90 in one. In this last instance (subject No. 35) the slope is 0.877 and the regression line crosses the isosmotic parameter with the consequence that the urine becomes hypotonic at flows above $10.7 \mathrm{cc}$. per minute.

Column 10 records the correlation coefficient for linear regression between $\mathrm{C}_{\text {osm }}$ and $\mathrm{V}$. The generally high value of this correlation coefficient was noted by Zak, Brun, and Smith who remarked that it implied both considerable relia- 
bility in the individual observations and regularity in the underlying physiological process.?

Column 11 records the mean value of $\mathrm{Tm}_{\mathrm{H}_{2} \mathrm{O}}^{\mathrm{c}}$ calculated as stated above and column 12 gives the ratio $\mathrm{Tm}_{\mathrm{H}_{2} \mathrm{O}}^{\mathrm{C}} / \mathrm{C}_{\mathrm{IN}}$. This ratio is more illuminating than the absolute values of $\mathrm{Tm}_{\mathrm{H}_{2} \mathrm{O}}^{\mathrm{C}}$, since it reveals the relative impairment of the two functions, concentrating operation and filtration rate.

This ratio varies widely in our subjects (from 1.5 to 8.8 ), but only slightly more so than in normal subjects: our mean value for this ratio is $5.2 \pm 1.9$, as compared with a mean value of $5.1 \pm 1.5$ in normal subjects. ${ }^{4}$ However, this ratio appears to vary with the underlying renal disease, as shown by Figure 2. In all subjects with an inulin clearance above $60 \mathrm{cc}$. per min. $\mathrm{Tm}_{\mathrm{H}_{2} \mathrm{O}}^{\mathrm{c}} / \mathrm{C}_{\mathrm{IN}}$ has a value of 5.3 or greater: whereas in 5 of 10 subjects with an inulin clearance below 60 cc. per min. this ratio is 3.1 or below. This suggests that in acute glomerulonephritis, and in some subjects diagnosed as chronic glomerulonephritis but in whom the disease has not progressed far as judged by reduction of the filtration rate, there may be a relatively greater reduction in glomerular activity than in concentrating power, probably in consequence of inflammatory changes or scarring of the glomerular tuft without obliteration of the subjoined tubule. Whereas in advanced glomerulonephritis, a low $\mathrm{Tm}_{\mathrm{H}}^{\mathrm{c}} \mathrm{O}_{\mathrm{O}} / \mathrm{C}_{\mathrm{IN}}$ ratio (Nos. $2,3,5,6,35$ ) suggests a relatively greater loss in concentrating power.

Table II records data obtained on 6 patients with renal impairment other than glomerulonephritis. In general, the results are much the same as those recorded for glomerulonephritis. The slope of the regression line lies between 0.90 and 1.10 in all cases except subject No. 9. This

\footnotetext{
We may add that one source of error ordinarily present in other clearance determinations, namely the independent measurement of the filtration rate, is not involved in the measurement of $\mathbf{C}_{\text {omm }}$.

The error involved in the measurement of the freezing point, $<1$ per cent, is probably less than that involved in colorimetric procedures generally. Lastly, errors involved in urine collection and timing affect $C_{\text {oem }}$ and $V$ almost proportionally. However, we must reaffirm that the high correlation coefficient implies, as Zak, Brun, and Smith stated, impressive regularity in the underlying physiological processes.

-We have calculated the mean value of this ratio from the data in Table I of Zak, Brun; and Smith.
}

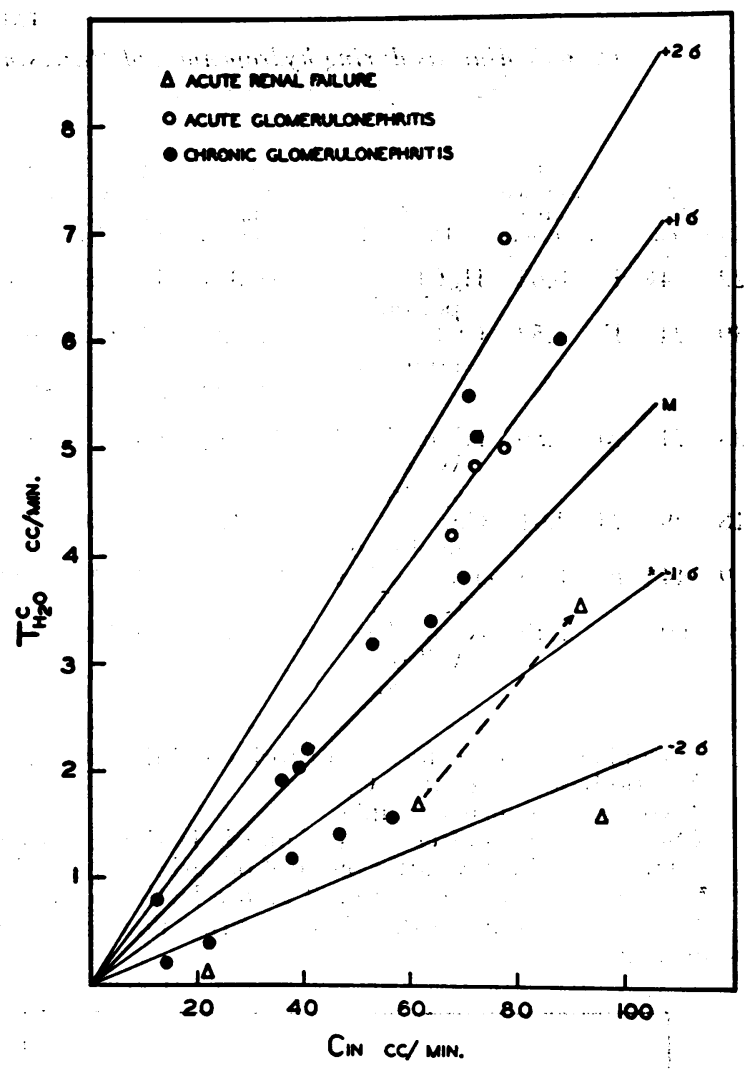

Fig. 2. Relationship of $\mathrm{Tm}_{\mathrm{H}_{2} \mathrm{O}}^{\circ}$ to $\mathrm{C}_{\mathrm{IN}}$ IN 19 SubJECTS WITH ACUTE OR CHRONIC GLOMERULONEPHRITIS AND 3.Subjects after ACUte Renal Failure

The data are superimposed on a curve representing the mean normal ratio \pm 1 and $2 \sigma$.

patient resembles subject No. 35 , in that there is coincidence between a low slope (0.824) and a marked increase in filtration rate ( 46 per cent) during osmotic diuresis, ${ }^{5}$ while the maximal urine flow represented 38 per cent of the simultaneous filtration rate and 55 per cent of the control filtration rate.

In 3 subjects studied shortly after an episode of acute renal failure (No. 22, mercury bichloride poisoning, No. 39, carbon tetrachloride poisoning, No. 9, transfusion reaction ${ }^{6}$ ) the ratio $\mathrm{Tm}_{\mathrm{H}}^{\mathrm{c} O} / \mathrm{C}_{\mathrm{IN}}$ was low : $1.7,2.8$, and $0.8 \mathrm{cc}$. per 100

Exclusive of this subject and No. 35, the greatest increase in filtration observed in any subject was 23 per cent... In general, however, we see no correlation between the regression coefficient and the maximal change in filtration rate during osmotic diuresis.

- It must be noted that the slope of the regression line in this subject is below $1.0(0.824)$ and the figure 0.18 represents the magnitude of $T_{\mathrm{H}_{2} \mathrm{O}}^{\circ}$ at the lowest urine flows. 
TABLE II

Osmotic diuresis during hydropenia and Pitressin (1) administration in six patients with renal diseases

\begin{tabular}{|c|c|c|c|c|c|c|c|c|c|c|c|c|c|c|}
\hline No.* & $\begin{array}{c}2 \\
\text { Age } \\
y+s .\end{array}$ & $\begin{array}{l}3 \\
\text { Sex } \\
\end{array}$ & $\begin{array}{c}\text { Surface } \\
\text { area } \\
\text { sq. } m . \\
\end{array}$ & $\begin{array}{c}5 \\
\text { Diagnosis } \\
\end{array}$ & $\underset{\substack{\text { Pange } \\
\text { mOsm./L. }}}{\mathbf{P}^{6}}$ & $\begin{array}{c}7 \\
\text { Urine } \\
\text { flow } \\
\text { range } \\
\text { cc./ming. }\end{array}$ & $\begin{array}{c}8 \\
\text { CIx } \\
\text { per } 1.73 \\
\text { eq. m. } \\
\text { cc. } / \mathrm{min} . \\
\end{array}$ & $\begin{array}{c}9 \\
\text { Regreas. } \\
\text { coef. } \\
\text { (dope) }\end{array}$ & $\begin{array}{c}10 \\
\text { Corred. } \\
\text { coef. } \\
r\end{array}$ & $\begin{array}{c}11 \\
\mathrm{Tm}_{\mathrm{Hio}}^{\circ} \\
\operatorname{per} 1.73 \\
\text { sq. m. } \\
\text { cc./min. }\end{array}$ & $\begin{array}{c}12 \\
\mathrm{Tm}_{\mathrm{ngo}}^{\circ} \\
\mathrm{Cln}^{\circ} \\
\times 100 \\
\end{array}$ & $\begin{array}{c}13 \\
\text { Maximalt } \\
\text { specific } \\
\text { Eravity }\end{array}$ & $\begin{array}{c}14 \\
\text { Maximait } \\
\text { Uomal } \\
\text { Poen }\end{array}$ & $\begin{array}{l}15 \\
\text { v/Cim } x \\
100 \text { (at } \\
\text { maximal } \\
\text { diureais) } \\
\text { per cent } \\
\end{array}$ \\
\hline 22 & 48 & $F$ & 0.62 & $\mathrm{HgCl}_{2}$ & $304-334$ & $5.7-9.5$ & 96.0 & 1.101 & 0.9999 & 1.59 & 1.7 & 1.012 & 2.52 & 26.0 \\
\hline \multirow[t]{2}{*}{39} & $24 \|$ & F & 1.52 & $\mathrm{CCl}_{4}$ & $302-326$ & $2.8-12,4$ & 61.1 & 1.061 & 0.9980 & 1.71 & 2.8 & - & 1.54 & 22.5 \\
\hline & & & & $108 \mathrm{~g}$ & 272-299 & $1.9-16,0$ & 91.3 & 0.999 & 0.9942 & 3.59 & 3.9 & - & 2.9 & 20.0 \\
\hline 33 & 71 & $\mathbf{M}$ & 1.50 & $\begin{array}{l}\text { Kimmelstiel- } \\
\text { Wilson } \\
\text { syndrome }\end{array}$ & $307-32 Q$ & $2.3-10.4$ & 34.0 & 1.046 & 0.9713 & 2.06 & 6.0 & 1.018 & 1.87 & 24.7 \\
\hline 18 & 29 & $\mathbf{M}$ & 2.01 & $\begin{array}{l}\text { Chronic } \\
\text { pyeloneph. }\end{array}$ & $319-324$ & $4.1-9.0$ & 25.5 & 0.961 & 0.9780 & 1.20 & 4.7 & 1.010 & 1.47 & 27.9 \\
\hline 9 & $44 \pi$ & $F$ & 1.56 & $\begin{array}{l}\text { Transfusion } \\
\text { reaction }\end{array}$ & $316-335$ & $1.0-10.8$ & 21.6 & 0.824 & 0.9999 & $0.18^{* *}$ & 0.8 & 1.011 & 1.14 & 38.0 \\
\hline 4 & 60 & $\mathbf{F}$ & 1.49 & $\begin{array}{l}\text { Kimmelstiel- } \\
\text { Wilson } \\
\text { syndrome }\end{array}$ & $310-330$ & $2.0-3.2$ & 11.9 & 1.041 & 0.9968 & 0.45 & 3.8 & 1.010 & 1.20 & 17.5 \\
\hline
\end{tabular}

\footnotetext{
* Numbers refer to the case histories and do not reflect the number of experiments done in this study.

t Ratio based on control $\mathbf{C}_{\mathrm{n} \text {. }}$.

Not on same urine samples.

Seventeen days after onset of anuria lasting 2 days and oliguria lasting 2 days.

Twenty-eight days after onset of oliguria lasting 9 days. Second series of observations performed 5 months later.

Seventeen days after onset of anuria lasting 5 days and oliguria lasting 9 days.

** Urine hypotonic to the blood at urine flows above $2 \mathrm{cc}$. per min. Recorded $\mathrm{Tm} \mathrm{m}_{\mathrm{g} 0 \mathrm{O}}$ is largest value observed at low urine flows.
}

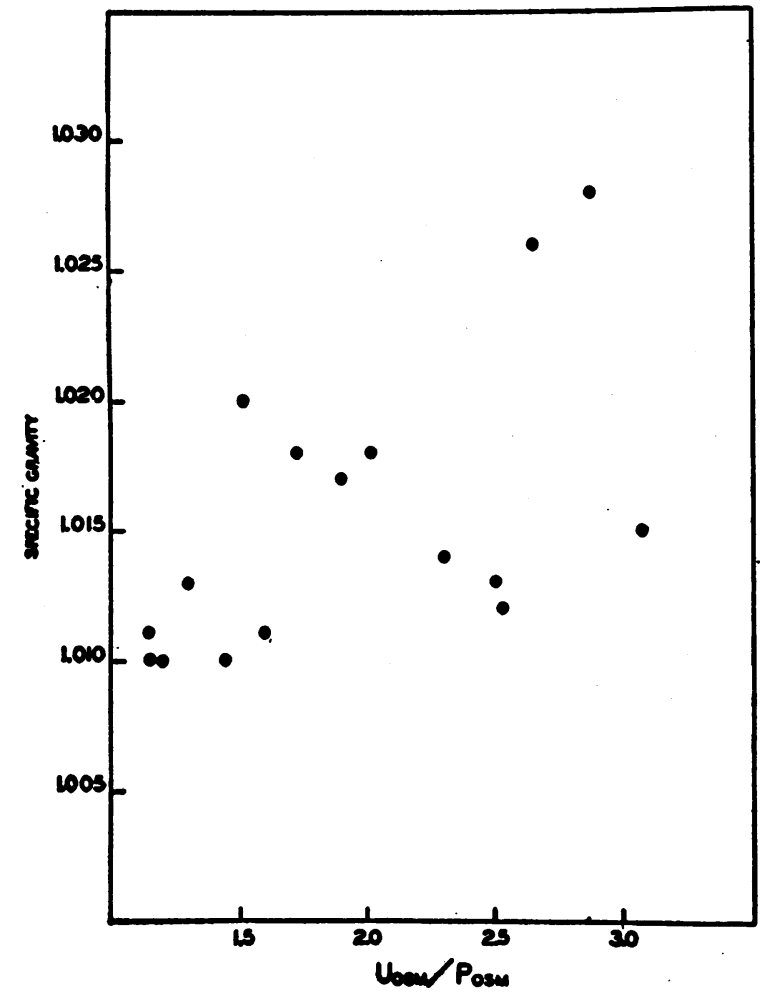

Fig. 3. Comparison of Urinary Spectfic Gravity and Osyotic U/P Ratio as Determaned by the CryoSCOPIC METhod cc. of filtrate (see Figure 2), as compared to 1.8, 2.6, and 2.7, the lowest ratios observed in normal subjects, and 1.5 and 1.9, the lowest ratios observed in subjects with glomerulonephritis. In subjects No. 22 and 39, however, the filtration rate was above $60 \mathrm{cc}$. per min., and these two subjects, if not subject 9 , bear out the presumption that concentrating capacity may be markedly impaired after acute renal failure, even at a time when the filtration rate has substantially recovered. Observations were repeated in subject No. 39 five months after recovery from acute renal failure. At this time the filtration rate had increased from 61 to $91 \mathrm{cc}$. per min., $\mathrm{Tm}_{\mathrm{H}, \mathrm{O}}^{\mathrm{c}}$ from 1.7 to $3.6 \mathrm{cc}$. per min., and the $\mathrm{Tm}_{\mathrm{H}_{2} \mathrm{O}}^{\mathrm{c}} / \mathrm{C}_{\mathrm{IN}}$ ratio from 2.8 to 3.9 , indicating further recovery of tubular function. In fact, the latter increased relatively more than did the filtration rate.

Column 13 records the maximal urinary specific gravity as determined by the usual clinical concentration test, i.e., after 15 to 18 hours' abstention from fluid. This measurement was made on the initial urine collected at the beginning of our observations. The ratio $\mathrm{Tm}_{\mathrm{H}_{3} \mathrm{O} / \mathrm{C}_{\mathrm{IN}}}^{\mathrm{c}}$ and maximal specific gravity are poorly correlated: subjects with ratios well above the mean 
normal value of 5.1 may have a maximal specific gravity of only 1.011 to 1.015 .

Column 14 gives the maximal osmotic U/P ratio observed in each patient. Figure 3 shows the relationship between specific gravity and osmotic $U / P$ ratio in the same urine samples, with selection of those samples showing the maximal specific gravity. The gross lack of correlation in Figure 3 is obvious. In the specific gravity range of 1.010 to 1.012 , ordinarily interpreted as indicating loss of "concentrating ability," one finds osmotic U/P ratios as high as 2.5 ; on the other hand, in one subject (No. 32), the specific gravity was 1.020 but the maximal osmotic $U / P$ ratio was only 1.51 .

Column 15 indicates the per cent of concurrently filtered water which was excreted during maximal osmotic diuresis. The administration of mannitol was relatively constant in all patients and not adjusted to the filtration rate and consequently higher plasma concentrations were undoubtedly obtained in patients with low filtration rates. This circumstance would explain the fact that there is a roughly inverse correlation between the fraction of filtered water excreted at the peak of diureses and the filtration rate.

\section{DISCUSSION}

Our observations show that a renal mechanism for the production of an osmotically concentrated urine persists throughout the course of glomerulonephritis. The tendency for the ratio $T_{\mathrm{H}_{3} \mathrm{O}}^{\mathrm{O}} / \mathrm{C}_{\mathrm{IN}}$ to be elevated early in the course of the disease suggests predominant glomerular damage. Maintenance of a normal ratio as the disease progresses suggests proportional glomerular and tubular impairment, probably in consequence of loss of function in entire nephrons. It is only in the most advanced stages of functional impairment that a markedly reduced $T_{\mathrm{H}_{2} \mathrm{O}}^{c} / \mathrm{C}_{\text {IN }}$ ratio provides evidence of a specific tubular defect, but here the reduction in ratio may be attributable to a relative increase in filtration rate. Our data are therefore inadequate to establish whether a defect in concentrating power is characteristic of glomerulonephritis. Certainly in many patients with fairly advanced disease (filtration rates of $40 \mathrm{cc}$. per min. or less) residual concentrating power is proportional to the residual filtration rate.
With respect to acute renal failure, our data show that concentrating capacity is reduced out of proportion to the reduction in filtration rate.

Among the 25 subjects examined here, the slope of the regression line lies between 0.90 and 1.10 in 14, and between 1.10 and 1.30 in $9 . \mathrm{We}$ can add nothing to the remarks of Zak, Brun, and Smith on the obscure factor or factors which cause this slope to deviate from 1.0, except to re-emphasize that, in view of the high coefficient of correlation with linear regression, this deviation must be considered to be physiologically significant.

It must be noted that in the two subjects (Nos. 35 and 9), where the slope of the regression line is very low (0.877 and 0.824 , respectively), the calculation of a maximal value of $T_{\mathrm{H}_{2} \mathrm{O}}^{\mathrm{O}}$ is at present meaningless since $T_{\mathrm{H}_{2} \mathrm{O}}^{\mathrm{C}}$ becomes negative at urine flows of 8.5 and $1.8 \mathrm{cc}$. per min., respectively; i.e., both subjects excreted a hypotonic urine during osmotic diuresis in spite of sustained hydropenia and the administration of Pitressin ${ }^{\circledR}$. Whatever the cause for the low slope, it operates consistently throughout the test, as shown by a high correlation coefficient (0.9905 and 0.9999$)$. The explanation of this deviation in slope, with respect to the presumed constancy of $\mathrm{T}_{\mathrm{H}_{2} \mathrm{O}}^{\mathrm{c}}$ at adequate urine flows, must remain for further investigation. It is perhaps significant that in both of these subjects, a relatively large fraction (67 and 55 per cent) of the filtrate as measured basally was excreted during osmotic diuresis; and that in both, the filtration rate increased markedly during osmotic diuresis.

At urine flows where $T_{\mathrm{H}_{2} \mathrm{O}}^{\mathrm{c}}$ has attained its maximal value, the osmotic $U / P$ ratio decreases with increasing osmotic diuresis in accordance with the relationship (which issues from equation 1):

$$
\frac{U_{\text {osm }}}{P_{\text {osm }}}=1+\frac{T_{\mathrm{H}_{0} \mathrm{O}}^{c}}{V}
$$

and neither $\mathrm{U}_{\text {osm }}$ nor $\mathrm{U}_{\mathrm{osm}} / \mathrm{P}_{\text {osm }}$ affords any direct information on the concentrating operation of the kidney, which is properly judged by $\mathrm{Tm}_{\mathrm{H}_{2} \mathrm{O}}^{\mathrm{c}}$ itself.

At progressively lower urine flows, as noted above, water reabsorption proceeds until the osmotic pressure of the urine, or the osmotic U/P ratio, approaches a maximal value. 
It is under conditions of oliguria, where this limitation applies, that the maximal urine specific gravity is generally measured. Discrepancies can be expected between urine specific gravity and osmotic concentration since the contribution of the several urinary constituents to specific gravity and osmotic concentration are quite different. ${ }^{7}$

Although our studies were not designed to examine the maximal osmotic: $U / P$ ratio per se, none of our subjects failed to elaborate urine of higher osmotic concentration than plasma, in spite of the fact that the specific gravity of the same short-period samples collected after 18 hours of fluid deprivation was 1.013 or less in 8 of the 16 instances in which the comparison was made. Three patients (Nos. 19, 37, 34) in the early stages of glomerulonephritis $\left(\mathrm{C}_{\mathrm{IN}}>60\right.$ cc. per min.) showed a maximal specific gravity of 1.013 to 1.015 , though the concentrating mech-

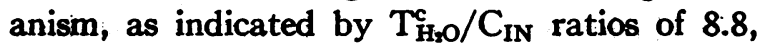
6.6, and 5.3, was well preserved. These subjects also showed good maximal osmotic U/P ratios $(3.28,2.30,2.50)$. It is clear that specific gravity is only an approximate index of osmotic concentration.

Data are not yet available on the relation of $\mathrm{Tm}_{\mathrm{H}_{\mathrm{H}} \mathrm{O}}^{\mathrm{c}}$, as measured during osmotic diuresis, and the maximal osmotic $U / P$ ratio during oliguria. It seems improbable that there exist two mechanisms for the reabsorption of solute-free water, one operating in oliguria and the second during osmotic diuresis. If it is accepted that the concentrating process represents a unitary mechanism operating at all urine flows, then when $\mathrm{Tm}_{\mathrm{H}, \mathrm{O}}^{\mathrm{c}}$, as measured during osmotic diuresis, is zero, the urine during oliguria must be isosmotic with the plasma, i.e., the osmotic U/P ratio will be 1.0, regardless of the urine flow. Conversely, where the oliguric osmotic $U / P$ ratio is 1.0 , it is not to be expected that $\mathrm{Tm}_{\mathrm{H}_{2} \mathrm{O}}^{\mathrm{C}}$ will have a positive value at any level of osmotic diuresis. But in as much as the maximal osmotic $U / P$ ratio may represent a limiting osmotic gradient across the renal tubules or collecting ducts (or less immediately, the ureters and bladder), it is conceivable that this ratio may be decreased in

\footnotetext{
7 We find no warrant for the rigid correlation between specific gravity and osmotic pressure implied by Figure 4 of Darrow and Pratt (8).
}

disease when $T m_{H, O}^{c}$ still retains a substantial value.

The difficulty in examining this question, and of quantitatively assessing the maximal osmotic $\mathrm{U} / \mathrm{P}$ ratio, is that in oliguria the kidney is in a mild but highly variable state of "osmotic diuresis": attributable to the continued excretion of urea creatinine, sodium chloride, etc. (9). Insofar as there is substantial splay at the intermediate urine flows where we pass from the parameter of maximal osmotic $U / P$ ratio to the parameter of $\mathrm{Tm}_{\mathrm{H}, \mathrm{O}}^{\mathrm{C}}$, the observed osmotic $\mathrm{U} / \mathrm{P}$ ratio may be significantly depressed by this "endogenous" osmotic diuresis. Our present values for the maximal osmotic $U / P$ ratio must therefore be looked upon as possibly less than "maximal." The measurement of the maximal $U / P$ ratio must await detailed studies of the experimental conditions under which it can be attained, in the normal as well as in the diseased kidney.

\section{CONCLUSION}

1. The urinary concentrating operation during osmotic diuresis and Pitressin administration has been examined in 25 hydropenic subjects with impaired renal function: 19 with acute or chronic glomerulonephritis, 1 with chronic pyelonephritis, 2 with Kimmelstiel-Wilson syndrome, and 3 with acute renal failure.

2. The quantity of solute-free water $\left(\mathrm{Tm}_{\mathrm{H}_{2} \mathrm{O}}^{\mathrm{C}}\right)$ required to restore the urine to an isosmotic state with respect to the glomerular filtrate was calculated as the difference between osmolar clearance and urine flow.

3. A concentrating operation of substantial magnitude was demonstrated in all subjects with glomerulonephritis. In five subjects with acute glomerulonephritis, who in all instances had a filtration rate $\left(C_{I N}\right)$ above $60 \mathrm{cc}$. per min., the ratio of $\mathrm{Tm}_{\mathrm{H}}^{\mathrm{c}} \mathrm{O}$ ranged from 5.3 to 8.8 , and thus exceeded the mean normal value of 5.1. We interpret these data as indicating that early in glomerulonephritis the filtration rate may be reduced without substantial impairment of the concentrating operation represented by $\mathrm{Tm}_{\mathrm{H}_{2} \mathrm{O}}^{\mathrm{c}}$. Conversely, in 10 subjects with chronic glomerulonephritis in whom the filtration rate was below $60 \mathrm{cc}$. per min., the ratio $\mathrm{Tm}_{\mathrm{H}_{3} \mathrm{O}}^{\mathrm{C}}$ was above $\mathbf{5 . 0}$ 
in five; in the rest, this ratio ranged from 3.0 down to 1.5. Our data are too limited to determine whether in advanced glomerulonephritis the concentrating operation may be consistently impaired out of proportion to impairment in filtration rate.

4. In the three subjects examined after an episode of acute renal failure, the ratio $\mathrm{Tm}_{\mathrm{H}_{5} \mathrm{O}}^{\mathrm{c}} / \mathrm{C}_{\mathrm{IN}}$ was so low that we infer the presence of specific damage to the concentrating mechanism.

5. The maximal specific gravity of urine collected after an 18-hour period of hydropenia does not in general correlate with either the magnitude of the concentrating operation as measured by $\mathrm{Tm}_{\mathrm{H}_{2} \mathrm{O}}^{\mathrm{C}}$, or with the osmotic $\mathrm{U} / \mathrm{P}$ ratio determined in these same samples. At a specific gravity of $\mathbf{1 . 0 1 3}$ or lower, osmotic $U / P$ ratios as high as $\mathbf{2 . 5}$ may be reached. This lack of correlation is clearly attributable to the fact that different solutes (sodium chloride, urea, etc.) contribute differently to osmotic pressure and to specific gravity.

\section{REFERENCES}

1. Wesson, L. G., Jr., and Anslow, W. P., Jr., Effect of osmotic and mercurial diuresis on simultaneous water diuresis. Am. J. Physiol., 1952, 170, 255.

2. Zak, G. A., Brun, C., and Smith, H. W., The mechanism of formation of osmotically concentrated urine during the antidiuretic state. J. Clin. Invest., 1954, 33, 1064.

3. Smith, H. W., The Kidney: Structure and Function in Health and Disease. New York, Oxford University Press, 1951.

4. Schreiner, G. E., Determination of inulin by means of resorcinol. Proc. Soc. Exper. Biol. \& Med., 1950, 74, 117.

5. Bowman, R. L., Trantham, H. V., and Caulfield, P. A., An instrument and method for rapid, dependable determination of freezing-point depression. J. Lab. \& Clin. Med., 1954, 43, 310.

6. Johlin, J. M., The freezing point determination of physiological solutions. The usual errors and their elimination. J. Biol. Chem., 1931, 91, 551.

7. Smith, H. W., Renal excretion of sodium and water. Federation Proc., 1952, 11, 701.

8. Darrow, D. C., and Pratt, E. L., Fluid therapy. Relation to tissue composition and the expenditure of water and electrolyte. J. A. M. A., 1950, 143, 365.

9. Platt, R., Renal failure. Lancet, 1951, 1, 1239. 